\title{
Commentary
}

\section{Clinical pharmacology in health care, teaching and research}

\author{
Michael D. Rawlins
}

National Institute for Health and Clinical Excellence, London, UK

Forty-two years ago the World Health Organization published a report that attempted to define the discipline of clinical pharmacology [1]. Since then, the scope of the discipline has expanded immeasurably. The number of available medicines has markedly increased, biological therapies are now having a profound impact on contemporary therapeutics and the range of conditions that can now be effectively managed by modern drug therapy is far greater than hitherto. Moreover, the impact of personalized medicine and pharmacogenetics is likely to change, fundamentally, the face of therapeutics in the future.

But there are other issues, too, about which clinical pharmacologists now have to be concerned. The high acquisition cost of some new pharmaceutical products, coupled with resource constraints on global health care budgets, renders issues about their cost effectiveness becoming as relevant in developed countries as they are in developing ones. And those hoary old chestnuts of quality and safety, as well as striking an appropriate balance between benefit and risk, remain.

It was therefore timely for the 1970 WHO report to be revised to take account of all these developments and Folke Sjöqvist, Michael Orme and Don Birkett have been masterminding its revision, now published as Clinical Pharmacology in Health Care, Teaching and Research [2], for several years. Together with an international group of contributors, they have overseen the preparation of a document that has been endorsed by WHO as well as by the International Union of Basic and Clinical Pharmacology (IUPHAR) and the Council for International Organizations of Medical Sciences (CIOMS).

This new report covers all the emergent, and emerging, issues. Some clinical pharmacologists might criticize it for failing to give sufficient attention to health technology assessment, health economics or pharmacoepidemiology. While I have inherent sympathies with these reservations, all these topics are discussed albeit briefly and, as a contributor to the report, I have to accept that to have gone into greater detail would have expanded the report to an extent that would have seriously diminished its impact.
The report also includes two important appendices. One is a 'model' undergraduate core curriculum in clinical pharmacology, therapeutics and prescribing for medical students. The other is a 'model' curriculum for medical specialization in clinical pharmacology. Both will, I am sure, become global training standards.

The report also recognizes, at least obliquely, the distinction between clinical pharmacology as a trade and as a discipline. The discipline of clinical pharmacology is far broader than the unique contributions that specialist clinical pharmacologists can themselves make. And here is the rub that has bedevilled our subject for two decades or more. The scope of clinical pharmacology is too broad for any of us to accomplish the totality with any degree of comfort. Or, as stated in the report, ${ }^{\prime}$... the list of ingredients in a contemporary clinical pharmacologist's work provides a menu too full for a single individual'. Necessarily, physicians trained in disciplines such as paediatrics, geriatrics, oncology and psychiatry carry out much important clinical pharmacological research and practice. Moreover, clinical pharmacology is undertaken by a new generation of prescribers in nursing and pharmacy. Significant research in clinical pharmacology is also performed by epidemiologists as well as by non-clinical personnel working in the pharmaceutical industry.

The report recognizes, indeed welcomes, the diversity of disciplines involved in the practice of clinical pharmacology both as prescribers and as investigators. It emphasizes the important contributions that individual specialists, in other disciplines, make to clinical pharmacology, but at the same time defining, more clearly than hitherto, the special contributions of clinical pharmacologists themselves for the well-being of patients and the public. For this, especially, Folke Sjöqvist, Michael Orme and Don Birkett deserve our enduring gratitude.

\section{Competing Interests}

The author has completed the Unified Competing Interest form at http://www.icmje.org/coi_disclosure.pdf (available 
on request from the corresponding author) and declares no support from any organization for the submitted work, no financial relationships with any organizations that might have an interest in the submitted work in the previous 3 years and no other relationships or activities that could appear to have influenced the submitted work.

\section{REFERENCES}

1 Clinical Pharmacology. Scope, organisation, training. Report of a WHO study group. World Health Organ Tech Rep Ser 1970; 446: 5-21.

2 Clinical Pharmacology in Health Care, Teaching and Research. Geneva: Council for the International Organizations of Medical Sciences, 2012.

\section{RECEIVED}

2 January 2013

\section{ACCEPTED}

2 January 2013

\section{ACCEPTED ARTICLE PUBLISHED ONLINE}

8 January 2013

\section{CORRESPONDENCE}

Professor Michael D. Rawlins MD, National Institute for Health and Clinical Excellence, 10 Spring Gardens, London SW1A 2BU, UK.

Tel.: +448450037780

Fax: +44845003 7784

E-mail:michael.rawlins@nice.org.uk 